\title{
262. CONFIRMACIÓN DE CITA HISTÓRICA PARA ACAROSPORA SCHLEICHERI (ACH.) A, MASSAI (ACAROSPORACEAE) EN ALMERÍA
}

\author{
Juan M. REQUENA MULLOR
}

Recibido el 28 de mayo de 2015, aceptado para su publicación el 1 de septiembre de 2015

Ratification of historic record for Acarospora schleicheri (Ach.) A, Massai (Acarosporaceae) in Almeria

Palabras clave. Liquen, terrícola, Acarospora, Sierra de Gádor, Almería.

Key words. Lichen, terricolous, Acarospora, Sierra de Gádor, Almería.

Durante los muestreos llevados a cabo para la recopilación y divulgación de la flora liquénica presente en la provincia de Almería se encontraron varios especímenes de Acarospora schleicheri (Ach.) A, Massai. Este hallazgo confirma una cita histórica (Colmeiro 1867) y añade un nuevo taxón a la flora de Andalucía.

Acarospora schleicheri es una especie terrícola presente principalmente en zonas áridas y semiáridas de Europa, África, Australia y Norte América (Eldridge, 1996; Brodo et al. 2001). En la Península Ibérica aparece sobre costras de yeso y suelos con $\mathrm{pH}$ de ácido a neutro (Crespo \& Barreno 1975; Ginés et al. 1989; Llimona \& Hladun 2001; Wirth et al. 2004), soportando un amplio rango de ombroclimas (Crespo \& Barreno 1978). Colmeiro (1867) recogió la presencia de la especie en las provincias de Málaga, Córdoba, Granada (sobre suelo y briófitos) y Almería, indicando para ésta última un comportamiento calcícola pero sin dar detalles más precisos de su localización. Posteriormente, Xavier Llimona y Jose María Egea realizaron numerosas prospecciones liquénicas en el sureste peninsular durante los años setenta y ochenta pero sin volver a encontrarla (Egea \& Llimona 1981; Egea \& Llimona 1983; entre otros). Recientemente, Burgaz (2014) trata la identificación de esta especie para Andalucía como dudosa aunque da como posiblemente ciertas las citas sobre suelo neutro.

Los ejemplares encontrados proceden del SO de la provincia de Almería, concretamente de la Sierra de Gádor. Se han contabilizado más de 50 individuos directamente sobre suelo y sobre talos de Diploschistes diacapsis (Ach.) Lumbsch. La población se encuentra sobre un glacis calcáreo de suelo arcilloso con $\mathrm{pH}$ ligeramente básico $(8.1 \pm 0.2)$ y abundantes afloramientos de roca en superficie (Pérez et al. 2004). El bioclima sigue pautas generales mesomediterráneas con ombrotipo seco, caracterizado por tener veranos secos y cálidos e inviernos fríos (con heladas ocasionales) y poco lluviosos. El hallazgo de Acarospora schleicheri confirma por tanto la cita de Colmeiro (1867), justifica su incorporación en la flora de Andalucía y aporta nuevos hallazgos sobre su comportamiento ecológico.

\section{Material estudiado}

Acarospora schleicheri (Ach.) A, Massai.

ALMERÍA. Sierra de Gádor. Venta de Cacín. Vegetación abierta no arbolada formada por matorrales de Macrochloa tenacissima (L.) Kunth y Phlomis purpurea L. UTM: 30S 0516685/4092607, $803 \mathrm{~m}$ de altitud. 29-03-2015. Leg: Juan Miguel Requena. Det: Juan Miguel Requena. HUAL-LICH-1. 
AGRADECIMIENTOS. Este trabajo ha sido posible gracias al trabajo desinteresado de los administradores y colaboradores de la web para la divulgación de la flora liquénica en Almería www. liquenesdealmeria.blogspot.com.es.

\section{BIBLIOGRAFÍA}

\section{BRODO, I. M., S. D. SHARNOFF \& S. SHARNOFF} -2001- Lichens of North America. Yale University Press/New Haven and London.

BURGAZ, A. R. -2014- Líquenes de Andalucía (S de España): catálogo bibliográfico y nuevos datos del NW del área. Botanica Complutensis 38: 53-88.

CRESPO, A. y E. BARRENO -1975- Ensayo florístico y ecológico de la vegetación liquénica de los yesos del centro de España (Fulgensietalia desertori ord. nov.) Anales. Inst. Bot. Cavanilles 32(2): 873-908.

CRESPO, A. y E. BARRENO -1978- Sobre las comunidades terrícolas de líquenes vagantes (Sphaerothallio-Xanthoparmelion vagantis al. nova). Acta Bot. Malacitana 4: 55-62.

EGEA, J. M. y X. LLIMONA -1981 - Líquenes silicícolas de la Sierra de los Filabres y Sierra Alhamilla (Almería, España). An. Univ. Murcia. Ciencias 37: 107-152.

EGEA, J. M. y X. LLIMONA -1983- Mapas de distribución en el SE de España de los principales líquenes silicícolas. I. An. Univ. Murcia. Ciencias 41: 209-256.

ELDRIDGE, D. J. -1996- Distribution and Floristics of Terricolous Lichens in Soil Crusts in Arid and Semi-arid New South Wales, Australia. Australian Journal of Botany 44: 581-599.

GINÉS, A., L. A. FIOL, A. POL \& J. A. ROSSELLÓ -1989- Morfologia I vegetació d'un grup de dolines de la Sierra de Tramuntana (Mallorca). Endins 14-15.

LLIMONA, X. y N. HLADUN -2001- Checklist or the Lichens and lichenicolous Fungi or the Iberian Peninsula and Balearic Islands. Bocconea 14: 5-581.
PÉREZ, A., C. OYONARTE, A. FERNÁNDEZ, R. BURGOS, M. QUESADA \& J. L. GUIRADO -2004- Mapa digital de suelos. Provincia de Almería: Alhama de Almería 1044. Madrid, Dirección General para la Biodiversidad. Ministerio de Medio Ambiente.

WIRTH, V., R. DÜLL, X. LLIMONA, R.M. ROS y O. WERNER -2004- Guía de campo de los Musgos, Líquenes y Hepáticas. Editorial OMEGA.

Dirección del autor. Universidad Almería. Centro Andaluz para la Evaluación y Seguimiento del Cambio Global (CAESCG). Carretera de Sacramento $\mathrm{S} / \mathrm{N}, 04120$. La Cañada de San Urbano (Almería). juanmir@ual.es 